\title{
ELEGIA: \\ PROPÉRCIO, TIBULO E OVÍDIO
}

José Rodrigues Seabra Filho*

(Universidade de São Paulo)

\begin{abstract}
RESUMO. O texto a seguir analisa aspectos da elegia, composição lírica originária da Grécia e explorada por poetas romanos da antiguidade. $\mathrm{O}$ valor de toda essa produção literária está tanto nos temas - pensamentos e reflexões dos poetas - como também no texto latino caracterizado por dísticos elegíacos de grande perfeição formal. Documentos hoje valiosos para estudiosos da cultura clássica e do latim.
\end{abstract}

PALAVRAS-CHAVE: Literatura latina; elegia; Tibulo; Propércio; Ovídio.

\section{ELEGY : \\ PROPERTIUS, TIBULLUS AND OVID}

\begin{abstract}
The following text analyzes aspects of elegy, a lyric composition originated in Greece and explored by ancient Roman poets. The value of all this literary production is both in the themes - thoughts and reflections of the poets - as well as in the Latin text characterized by elegiac couplets of great formal perfection. Today valuable documents for scholars of classical culture and Latin.
\end{abstract}

KEYWORDS: Latin literature; elegy; Tibullus; Propertius; Ovid.

Composição característica mais exatamente da poesia lírica, a elegia tem sua origem na Grécia antiga (séculos VIII e VII a. C.). No início a elegia talvez fosse música para funerais, para acompanhar enterros, poesia triste e plangente; mais adiante, a elegia vai abordar vários assuntos: a virtude, o dever cívico, variações das situações humanas, brevidade da existência etc. Pela base $-\lambda \varepsilon \gamma-$ o nome $\varepsilon) \lambda \varepsilon \gamma \varepsilon l / \alpha$ pode estar relacionado com $\lambda \varepsilon / \gamma \varepsilon \imath v$ (dizer).

Roma a elegia começa a ser cultivada a partir da segunda metade do século I a. C. Tratase então de forma literária já bem definida: estrofe de dois versos - o dístico elegíaco, caracterizado por hexâmetro e pentâmetro. Assuntos diversos como a elegia grega, mas em geral prevalece o amoroso, tanto o relativo ao amor sentimental como ao sensual. Não se pode dizer com certeza que a elegia romana representa poesia romântica sincera, poesia que reflete drama pessoal vivido; provavelmente seja mais transposição literária de paixão real mas sublimada pela arte e lapidada pela tradição estética. Sobressaem na elegia romana Tibulo, Propércio e Ovídio, poetas contemporâneos que produziram durante a época de Augusto, período áureo para a literatura latina, e em especial para a poesia.

\footnotetext{
*E-mail: ricklou@usp.br
} 
Dos quatro livros de elegias atribuídos a Tibulo, só os dois primeiros são autênticos de poemas desse poeta; os livros III e IV contêm peças também de outros autores. Dentre os temas de Tibulo sobressai uma apologia da vida simples do campo, do viver com pouco. O campo é amado por tudo o que nele há: selvas, riachos, paisagens, animais. Daí, encontrar-se em seu texto, logo na primeira peça, numa dedicatória em dístico elegíaco, a apóstrofe à deusa da agricultura (I, 1, 15-16):

Flaua Ceres, tibi sit nostro de rure corona spicea quae templi pendeat ante flores.

[Loura Ceres, para ti seja de nosso campo uma coroa de espigas que penda ante as flores de teu templo.]

Daí também na primeira peça do segundo livro, em dois dísticos, a preocupação com a purificação do ambiente campestre (II, 1, 17-20):

Di patrii, purgamus agros, purgamus agrestes, uos mala de nostris pellite limitibus.

Neu seges eludat messem fallacibus herbis,

Neu timeat celeres tardior agna lupos.

[Deuses pátrios, purgamos os campos, purgamos os camponeses; quanto a vós, afastai de nossas fronteiras os males.

Que por hervas enganosas a seara não frustre a colheita, que mais vagarosa ovelha não tema os céleres lobos.]

O obsessivo amor ao campo dá à elegia um aspecto de poema também pastoril, pelo menos quanto ao ambiente e às imagens (II, 3, 1-14):

Rura meam, Cornute, tenent uillaeque puellam: ferreus est, heu heu, quisquis in urbe manet. Ipsa Venus latos iam nunc migrauit in agros uerbaque aratoris rustica discit Amor.

$O$ ego, cum aspicerem dominam, quam fortiter illic uersarem ualido pingue bidente solum agricolaeque modo curuum sectarer aratrum, dum subigunt steriles arua serenda boues! Nec quererer quod sol graciles exureretartus, laederet et teneraspussularuptamanus. Pauit et Admetitaurosformosus Apollo, nec cithara intonsae profueruntue comae, nec potuit curas sanare salubribus herbis: quidquid erat medicae uicerat artis amor.

[Os assuntos rurais, Cornuto, e as quintas retêm minha menina; é de ferro ai! ai! todo aquele que permanece na cidade.

A própria Vênus já agora migrou para os largos campos, e o Amor aprende as palavras rústicas do lavrador.

Oh! eu, quando olhasse a dona, quão fortemente ali volvesse com válida pingue ovelha o solo, e do agricultor seguisse há pouco o curvo arado, enquanto estéreis vacas lavram terras que devem ser semeadas! Nem me queixaria porque o sol queimasse as gráceis articulações e ferisse com pústula rompida as tenras mãos. Alimentou também os touros de Admeto o formoso Apolo, 
ou nem com a cítara as intonsas comas foram úteis, nem foi possível sanar curas com salubres ervas: ao que quer que havia de medicinal arte, o amor vencera.]

Agora com relação a Propércio, vemos que predominam aí os temas amorosos: do total de 92 elegias desse poeta, distribuídas em 4 livros, 67 são sobre o amor. O amor por Cíntiaaparece em episódios sem ligação, como capítulos avulsos de um romance. O início do primeiro livro dá o tom predominante relativo a esse aspecto (I, 1, 1-2):

Cynthia prima suis miserum me cepitocellis, contactumnullis ante cupidinibus.

[Cíntia a primeira que com seus olhinhos me conquistou, a mim, mísero,

não tocado antes por desejo nenhum.]

Sobre o valor de seu texto literário, as elegias propercianas sobressaem pelas reflexões acerca da psicologia do amor e acerca da psicologia feminina. A curta elegia 11 do livro II exemplifica bem a mulher que serve de tema:

Scribant de te aliiuel sis ignotalicebit:

laudetqui steriliseminaponit humo.

Omnia, crede mihi, tecum uno munera lecto

auferet extremi funeris atra dies;

et tua transibit contemnens ossa uiator

nec dicet: "Cinis hic docta puella fuit".

[Escrevam de ti outros, ou que fiques desconhecida:

que te louve aquele que em estéril terra põesementes.

A todos os teus dons, crê em mim, juntamente contigo, em um único leito

o sombrio dia de teu último funeral arrebatará;

e desprezando teus ossos um viajante passará

e não dirá: "Esta cinza foi uma douta menina".]

No verso final cinis hic a tradução pode ser "esta cinza", pois em latim "cinis" aparece mais como nome masculino - e daí hic pode estar como forma masculina do pronome demonstrativo -, mas pode ser também "a cinza aqui (neste lugar)", pois hic pode aparecer aí como advérbio de lugar. A expressão extremi funeris atra dies [de/teu/ extremo funeral o negro dia] indica o dia da morte da menina: esta, durante toda a sua vida, poderia ter comparecido a outros funerais; o último é o dela mesma. Enfim o texto reclama da mulher-tema, da musa que não corresponde aos anseios de quem escreve sobre ela; daí o desconsolo desse poeta (scribant de te alii), daí a advertência do fatal último dia de existência que haverá de chegar, e a advertência do que sobrará (cinis hic) de todos os predicados femininos.

Ainda da mesma geração mas um pouco mais novo que os anteriores aparece como elegíaco Ovídio, cuja obra, mais diversificada que a de Tibulo e Propércio, em grande parte se constitui de elegias. Entre as produções iniciais constam Amores e Heroides. Trata-se a primeira de série de elegias amorosas, em três livros, em que o poeta celebra sua musa Corina, personagem simbólica. Heroides, cartas imaginadas, em versos elegíacos, de heroínas dos tempos mitológicos; Tristia, cinco livros de elegias (Tristium libri V). Estas últimas, escritas no exílio,em número de 50 distribuídas pelos 5 livros, caracterizam-se, quanto à construção, por perfeição formal, e quanto aos assuntos, por informações biográficas do poeta, manifestações 
pessoais, sofrimentos provocados pelo exílio - o que passa a impressão da volta daquela inicial e tradicional elegia chorosa. Como exemplo, a última elegia do livro IV apresenta-se em seus 132 versos como peça totalmente autobiográfica de Ovídio. Assim é desde os dois dísticos iniciais (vv. 1-4):

Ille ego qui fuerim, tenerorum lusor amorum, quem legis, ut noris, accipe, posteritas.

Sulmo mihi patria est gelidis uberrimus undis milia qui nouies distat ab Vrbe decem.

[Aquele que tenha sido eu, gracejador de tenros amores, que lês, a fim de que tenhas conhecido, recebe, ó posteridade.

Sulmona me é a pátria fecundíssima em gélidas ondas, a qual dista nove vezes dez milhas da cidade /de Roma/.] $\mathrm{O}$ pendor para a atividade poética já se lhe manifestava desde a juventude, como revelam os quatro dísticos seguintes (vv. 19-26):

At mihi iam puero caelestia sacra placebant inque suum furtim Musa trahebat opus.

Saepe pater dixit: "Studium quid inutile temptas?

Maeonidesnullasipsereliquit opes."

Motus eram dictis totoque Helicone relicto

scribere temptabam uerba soluta modis.

Sponte sua carmen numeros ueniebat ad aptos, et quod temptabamscribereuersus erat.

[Mas a mim já menino agradavam as celestes coisas sacras, e furtivamente a Musa me arrastava para seu trabalho.

Muitas vezes meu pai disse: "Por que tentas estudo inútil? O próprio Meônidas (Homero) não deixou nenhuma riqueza."

Eu ficava abalado por essas palavras e, deixado o Helicão todo, tentava escrever palavras desprovidas de ritmos.

Por si mesmo um poema vinha para as medidas adequadas, e o que eu tentava escrever era verso.]

São também em versos elegíacos as epístolas que Ovídio imagina como dirigidas a seus amados por heroínas da tradição literária grega; em sequência de 21 epístolas, constituem as Heroides, obra anterior as Tristia. Justificação da métrica empregada aparece no início da epístola fictícia número 15, imaginada como de Safo a Faão (Heroides XV, 1-6):

\section{Ecquid ut inspecta est studiosae litera dextrae}

protinus est oculis cognita nostra tuis?

An, nisi legisses auctoris nomina Sapphus, hoc breue nescires unde ueniret opus?

Forsitan et quare mea sint alterna requiras carmina cum lyricis sim magis apta modis.

[Por acaso logo quando foi examinada a letra de uma estudiosa destra, imediatamente foi conhecida por teus olhos a nossa?

Acaso, se de nomes de autor não tivesses lido o de Safo, não saberias donde viria esta breve obra?

Talvez também requeiras por qual causa meus versos sejam alternados, quando eu seja mais apta às medidas líricas.] 
Os alterna carmina são aí referência ao dístico elegíaco que a poetisa estaria agora utilizando (de Safo seria normalmente mais variada a métrica, mais curtos os versos, mais apropriados para o canto acompanhado da lira os poemas). Mas mesmo que não seja destinada ao canto com lira ou com outro instrumento musical, também se inclui no gênero lírico - por ser manifestação de sentimentos e pensamentos do poeta - a elegia. Ora o tema mais tradicional desse tipo de composição é indicado a seguir (versos 7 e 8):

flendus amor meus est; elegia flebile carmen;

non facit ad lacrimas barbitos ulla meas

[meu amor deve ser chorado; elegia, poema choroso;

nenhum alaúde é útil às minhas lágrimas].

Em conclusão, quando se confrontam os textos dos três mais característicos elegíacos romanos fica evidente que o tema aí predominante é o amoroso; assim se constata na relação entre o poeta elegíaco e sua musa: tanto em Tibulo com sua paixão por Délia e por Nêmesis, como em Propércio por Cíntia, e em Ovídio por Corina. Neste tema o primeiro vê no amor total e sexual e sentimental o sentido da existência; o segundo se caracteriza por paixão exagerada e calor erótico; o terceiro por visão menos romântica e mais autozombeteira do envolvimento amoroso.

\section{BIBLIOGRAFIA}

Tibullialiorumquecarminumlibritres (ScriptorumClassicorumBibliothecaOxoniensis). Oxford UniversityPress, 1990.

PROPERCE - Élégies (éd. D. Paganelli). Paris, Les Belles Lettres, 1980.

OVIDE - Tristes (éd. Jacques André). Paris, Les Belles Lettres, 1968. 